\title{
An Empirical Analysis and Promotion Strategy Based on Evaluation of Entrepreneurial Education Capacity Based on CIPP Perspective: A Case Study of Jiangxi Province
}

\author{
Lei Zhao \\ Jiangxi Agricultural University, Nanchang, Jiangxi, China, 330045
}

Keywords: evaluation of entrepreneurial education; CIPP perspective; case study

\begin{abstract}
At present, China's efficient innovation and entrepreneurship education has not yet established a practical operational quality evaluation system. This study takes Jiangxi Province as an example to introduce the CIPP evaluation model into the evaluation system of efficient innovation and entrepreneurship education. Based on the connotation of the CIPP model, the document analysis method, Delphi method, and analytic hierarchy process are used to construct the entrepreneurial environment and entrepreneurial resources, education process and entrepreneurial effectiveness 4 first-level indicators, and 12 secondary indicators of efficient innovation and entrepreneurship education quality evaluation system.
\end{abstract}

\section{Introduction}

Under the background of inspiring innovation to drive development strategies and adapting to the new normal of economic development, China's new economic models and new business models have continued to emerge. The situation of "mass entrepreneurship and innovation" has gradually become a common practice in the society and has led to innovation and entrepreneurship education in colleges and universities [1, 2]. Higher education has become an important channel for transporting innovative and entrepreneurial talents from all walks of life. Under this background, the reform of innovation and entrepreneurship education in colleges and universities is in full swing, but the quality and effect of reforms need to be further verified and studied. In other words, how to evaluate the quality of innovation and entrepreneurship education in colleges and universities has become a hot and difficult issue in recent research. After the research on the quality evaluation system of innovation and entrepreneurship in universities in China, we found that research on the effectiveness of innovation and entrepreneurship education and the attainment of goals are more and more, and fewer studies are needed to evaluate and improve the quality of innovation and entrepreneurship education. The weight of indicators determines the tendency is more prominent, the logic and relevance between the indicators are poor, and the objectivity and rationality of the evaluation results are difficult to guarantee [3-6]. Therefore, as one of the important links in innovation and entrepreneurship education in universities, the research on the evaluation system of innovation and entrepreneurship education quality is particularly urgent. In view of the above issues, this study first introduces the universal CIPP education evaluation model into the evaluation system of innovation and entrepreneurship education quality in colleges and universities to solve the problem of poor logic and association between indicators, which can also be used to enrich the quality of business school innovation and entrepreneurship education. Secondly, aiming at the lack of scientific quality system of innovation and entrepreneurship education in universities in China, we use the literature analysis method, Delphi method and AHP to design and construct a systematic, scientific and operational quality evaluation system of innovation and entrepreneurship education in colleges and universities. The details of the CIPP method are given in figure 1. 


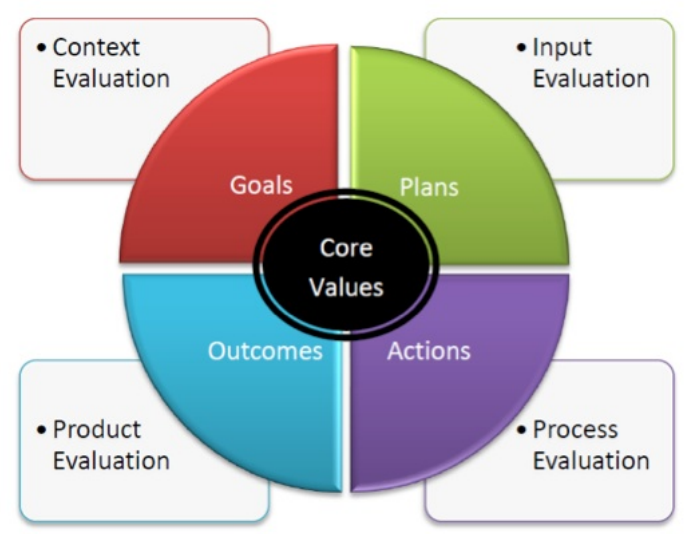

Figure 1. Details of CIPP

\section{Connotation Analysis of CIPP Education Evaluation Model}

The CIPP model was proposed by the national education [7, 8]. The background evaluation, input evaluation, process evaluation and achievement evaluation are the evaluation models for evaluation. The first letter combination of the four evaluation elements is CIPP. Stafferbym believes: "Feeding information for decision makers, policy makers, universities, teachers, and other people who are evaluating the information so as to improve education quality is the most valuable evaluation." The essence of this model is that "the main purpose of evaluation is not to prove it, but to improve it." The intrinsic evaluation in the CIPP model refers to the assessment of needs, problems, resources, and opportunities in a specific environment. It is essentially a diagnostic evaluation of program objectives. The input evaluation refers to the assessment of the resources, tools, methods, etc. that are available and may be obtained. In addition, it is essentially the feasibility evaluation of the implementation plan. Process evaluation refers to the supervision and inspection of the implementation of the implementation plan. It is essentially an evaluation of the efficiency of the execution plan. Outcome evaluation refers to the assessment of the degree of achievement of goals, and is essentially a formative evaluation of the plan.

The CIPP education evaluation model follows the method of systematic analysis. Based on the decision-making, organization, implementation and results encountered during the analysis of planning and implementation, as well as the decision-making plasticity of recycling, the CIPP education evaluation model in turn proposes backgrounds, inputs, and procedures. In the four evaluation elements of the achievement, the class decision and evaluation are related, and the background evaluation is planning decision service. Currently, the CIPP education evaluation model has a wide range of applications and is universally applicable. It has been widely used in the quality evaluation of various types of education. The reason is that this model has three advantages over other education evaluation models: The first is that the model conforms to the objective requirements of various types of education, which focuses on feedback functions and the process evaluation and improvement evaluation [9]. The second is to emphasize the decision-making function of education evaluation to provide decision-making services which can improve the value of teaching services. The third is the integration of planning, organization, implementation and results, as well as the four aspects of the decision-making of recycling, the corresponding formation of back-invaluable, input, process and results evaluation. Therefore, the CIPP model also fits the quality evaluation of the Pioneering School's innovation and entrepreneurship education.

\section{Construction of Evaluation Index System for Innovation and Entrepreneurship Education in Colleges and Universities from the Perspective of CIPP}

The quality evaluation index system for innovative and entrepreneurial education in colleges and universities is based on the evaluation goal of innovation and entrepreneurship education in colleges and universities to determine the specific evaluation criteria that can reflect the quality of education. 
Determine the Index of Innovation and Entrepreneurship Education for School Leavers. The evaluation target for the quality evaluation system of innovation and entrepreneurship education in business schools is business schools, and it is exactly the innovation and entrepreneurship education in business schools.

First of all, it is necessary to clarify the goals of innovation and entrepreneurship education in colleges and universities. We use literature analysis distinguish clearly innovation, entrepreneurship and innovation objectives connotation of entrepreneurship education in colleges and universities innovation, this is because the innovation and entrepreneurship education indicators in order to effectively detect only clear their innovation and entrepreneurship education degree to achieve their goals and to get the decision-making Meaningful evaluation conclusion. Innovation and entrepreneurship are two concepts which are both independent and interrelated. There are great differences in their internal meaning, status and goals. In terms of connotation, innovation is a conceptual process characterized by new thinking, new inventions, and new descriptions. Entrepreneurship is the process of creating valuable new things or careers through innovative practices. From the standpoint of status, innovation is a national strategy. From the perspective of goals, innovation education is for development, and entrepreneurship education is for the benefit of the people. Innovation is the fundamental strategy for the country to start worrying. Entrepreneurship is an effective way to relieve employment pressure, solve employment problems, and solve survival problems. Therefore, we should follow the "innovation lead the entrepreneurship, entrepreneurship to create jobs" principle in the implementation of innovation and entrepreneurship education, to cultivate the students' innovative spirit a little, sense of innovation and creativity, thus ensuring the correctness of the direction of innovation and entrepreneurship education. As shown in table 1, the analytic hierarchy process scale is given in details.

Table 1. Analytic hierarchy process scale

\begin{tabular}{|c|c|}
\hline Scale & Definition \\
\hline 1 & The comparison of two factors is of equal importance \\
\hline 3 & The former is slightly more important than the latter \\
\hline 5 & $\begin{array}{l}\text { Compared with the two elements, the former is obviously more important than the } \\
\text { latter }\end{array}$ \\
\hline 7 & Compared with the latter, the former is more important than the latter \\
\hline 9 & Compared with the two elements, the former is more important than the latter \\
\hline $2,4,6,8$ & importance is located in the middle of the above adjacent values \\
\hline $1-9$ & $\begin{array}{l}\text { The reciprocal of 1-9 compares the two factors, the latter is more important than } \\
\text { the former }\end{array}$ \\
\hline
\end{tabular}

\section{Construct an Evaluation Index System for Innovation and Entrepreneurship Education in Colleges and Universities}

The quality evaluation index system of innovation and entrepreneurship in colleges and universities under the perspective of CIPP model is a combination of background, input, process, and achievements. It combines process evaluation with result evaluation, subjective evaluation, and objective evaluation, and consists of entrepreneurial environment, entrepreneurial resources, and education. The process and the results of the venture consist of 4 first-level indicators, 12 second-level indicators, and 50 observation points. The first is to initially draft the index system. In combination with the CIPP model, the four evaluation dimensions of innovation and entrepreneurship education in colleges and universities are determined, which are the entrepreneurial environment that is in line with the background evaluation, which including the off campus entrepreneurial environment and the campus entrepreneurial environment. It is a prerequisite for the development of innovative entrepreneurship education in colleges and universities; The appropriate entrepreneurial resources, including human resources, financial resources, and organizational resources in innovation and entrepreneurship education, are the guarantees of innovation and entrepreneurship education in 
colleges and universities. As shown in table 2, the weight of evaluation system of innovation and entrepreneurship education in colleges and universities is given in details.

Table 2. The Weight of Evaluation System of Innovation and Entrepreneurship Education in Colleges and Universities

\begin{tabular}{|c|c|c|c|}
\hline First-level indicators & Weights & Second-level indicators & Weights \\
\hline \multirow{3}{*}{$\begin{array}{c}\text { Entrepreneurial } \\
\text { environment }\end{array}$} & \multirow{3}{*}{0.1471} & Regional Environment & 0.2412 \\
\hline & & Top-level design & 0.3602 \\
\hline & & technical foundation & 0.3986 \\
\hline \multirow{3}{*}{ Venture Capital } & \multirow{3}{*}{0.3845} & Teacher investment & 0.5032 \\
\hline & & Capital investment & 0.2145 \\
\hline & & Institution building & 0.2823 \\
\hline \multirow{3}{*}{ Education process } & \multirow{3}{*}{0.2653} & Entrepreneurship courses & 0.4437 \\
\hline & & Venture Project & 0.2764 \\
\hline & & Management process & 0.2799 \\
\hline \multirow{3}{*}{$\begin{array}{l}\text { Entrepreneurial } \\
\text { achievements }\end{array}$} & \multirow{3}{*}{0.2031} & Quality improvement & 0.3256 \\
\hline & & Entrepreneurial effect & 0.3376 \\
\hline & & Social benefits & 0.3368 \\
\hline
\end{tabular}

It is the core of the innovation and entrepreneurship education in colleges and universities; the achievement of entrepreneurship in conjunction with the achievement evaluation, which includes the degree of achievement of the $\mathrm{H}$-indicator of innovation and entrepreneurship education and social influence. Starting from the above four dimensions, hierarchical stratification, preliminary draft a more comprehensive business school creative innovation, education quality evaluation index system. There will be some duplication and overlap in the indicators that are initially drafted, and the directionality and independence of the indicators will also be poor. The second is to use the Delphi method, which is an expert opinion method to screen indicators. Delphi method is a group decision-making method with feedback, anonymity and statistical characteristics. The essence of this is that experts rely on their professional knowledge and professional experience to make judgments by subjectively judging the rate of interest. In the process, through consultations, feedback, and revisions, the experts ultimately make decisions on decision-making. Therefore, this method is particularly suitable for the lack of historical data and total information, and the analysis and prediction of the content of the product affected by related factors. In this study, we selected a total of 20 experts engaged in innovation and entrepreneurship education research scholars, practical teachers who have worked for more than 3 years and full-time teachers and innovation and entrepreneurship education institutions to conduct questionnaire surveys. A total of three rounds of consultation experts and 54 effective expert consultation questionnaires are conducted. In the consultation questionnaire of the three rounds of experts, the experts put forward many constructive suggestions, such as suggesting that the first-level indicator "entrepreneurial process" be revised to "educational process"; the second-level indicators of the K-domain environment in the entrepreneurial environment should be added; some indicators consolidation is conducted and evaluations are conducted in the best way possible with the most observable observations to prevent opinions from the subjective opinions of the appraisers during the evaluation process. At the same time, the statistical data of the collected effective expert consultation questionnaires were statistically analyzed and calculated through expert authority, expert coordination coefficient, and the number of mutations used by each indicator. After several consultations, feedbacks, revisions, and adjustments, the final statistics showed that each coefficient of variation of the indicators is below 0.2 , which indicates that the opinions of the experts on the indicators are consistent in the degree of coordination. Finally, four first-level indicators and 12 second-level indicators for the quality evaluation system of innovation and entrepreneurship education in commercial schools are set forth. Finally, it is clear enough to 
make clear observation points, evaluation methods, and exclamations. Focusing on the first-level and second-level indicators, integrating process evaluation and results evaluation, and reviewing and subjective evaluation, 52 observation sites for efficient innovation and entrepreneurship education in Jiangxi province were identified, and evaluation methods and investigation contents were clearly defined. The expert evaluation is divided into experts, and the evaluation levels are A, B, C, D, and E. They are respectively excellent, good, medium, qualified, and unqualified. The assigned values are 100-90, 89-80, and 79-70 points, $69-60$ points and $<60$ points. In addition to the total number of teachers, institutions, organization, innovation and entrepreneurship textbooks, and outstanding entrepreneurship alumni, etc., all are average data for the past three years.

\section{Summary}

At present, China's efficient innovation and entrepreneurship education has not yet established a practical operational quality evaluation system. This study took Jiangxi Province as an example to introduce the CIPP evaluation model into the evaluation system of efficient innovation and entrepreneurship education. Based on the connotation of the CIPP model, the document analysis method, Delphi method, and analytic hierarchy process were used to construct the entrepreneurial environment and entrepreneurial resources.

\section{Acknowledgement}

This work was supported by Provincial Education Science Plan (17YB036) . The authors gratefully acknowledge these supports.

\section{References}

[1] Zixiang H. Exploratory Study on Measurement of Service Quality in Higher Education [J]. Modern University Education, 2006, 2: 012.

[2] Hussain R, Othman N. Entrepreneurship module in community colleges Malaysia[J]. International Journal of Trade, Economics and Finance, 2013, 4(6): 425.

[3] Hussain R, Othman N. Evaluation on Entrepreneurship Module in Community Colleges: Students" and Lecturers" Perspectives[J]. International Journal of Information and Education Technology, 2014, 4(3): 281.

[4] Culver S. Educational quality, outcomes assessment, and policy change: the virginia example[J]. International Education, 2010, 40(1): 6.

[5] Errasti N, Bezanilla M J, García-Olalla A, et al. Factors and maturity level of entrepreneurial universities in Spain[J]. International Journal of Innovation Science, 2018 (just-accepted): 00-00.

[6] Carnegie T A M. Integrating context into assessing US technical communication programs[J]. Technical Communication, 2007, 54(4): 447-458.

[7] Kpolovie P J, Obilor I E, Ololube N P. Merits and Worth of National Open University of Nigeria as Distance Education Intervention[J]. Handbook of research on enhancing teacher education with advanced instructional technologies, 2015: 83-119.

[8] Dwaraczyk W J. Assessing a change effort in a division of a University library[M]//Advances in Library Administration and Organization. Emerald Group Publishing Limited, 2002: 27-58.

[9] Al Lily A E, full list of authors, see end. Academic domains as political battlegrounds: A global enquiry by 99 academics in the fields of education and technology[J]. Information Development, 2017, 33(3): 270-288. 